\title{
User Information Risk: How It Improves Audit Quality
}

Jack R. Ethridge, Stephen F. Austin State University, USA

Treba Marsh, Stephen F. Austin State University, USA

\begin{abstract}
Audited financial statements are the basis for the communication of essential financial information. Accordingly, the reliability of the financial statements is of extreme importance to all parties involved in the process. This paper identifies the three primary parties as the organization, the auditor, and the user and recommends the user play an increased role in this process. The user should be allowed to analyze the quality of the auditor and audit process based upon five critical factors that should be required to be disclosed by the auditor. This paper discusses the five factors and how each one could benefit the user's analysis of audit quality.
\end{abstract}

Keywords: Auditor; audit process; risk; disclosures; materiality

\section{INTRODUCTION}

$\mathscr{A}$

udited financial statements are the foundation for the communication of financial information. In this information cycle, there are three major parties: the organization, auditor, and user. All three have a vested interest in the reliability of the information and are faced with the risk that unintentional or intentional errors may be present. Users of financial statements need the information to make economic decisions. The organization may need to attract new or additional investments and maintain, or increase its stock value. Lastly, the auditor needs to be free of the potential pressures and consequences of being associated with misleading financial statements. Therefore, all three parties have a vested interest in assuring the reliability of the financial statements.

In the past, the primary responsibility has been placed on the organization and auditor to assure the reliability of the financial information. The user should be allowed to play an integral part in the process by being given the opportunity to independently evaluate the quality of the audit process and the information presented. The reliability of financial information should be a function of the three parties as presented in Figure 1.

Figure 1: Financial Statement Reliability - Principal Parties

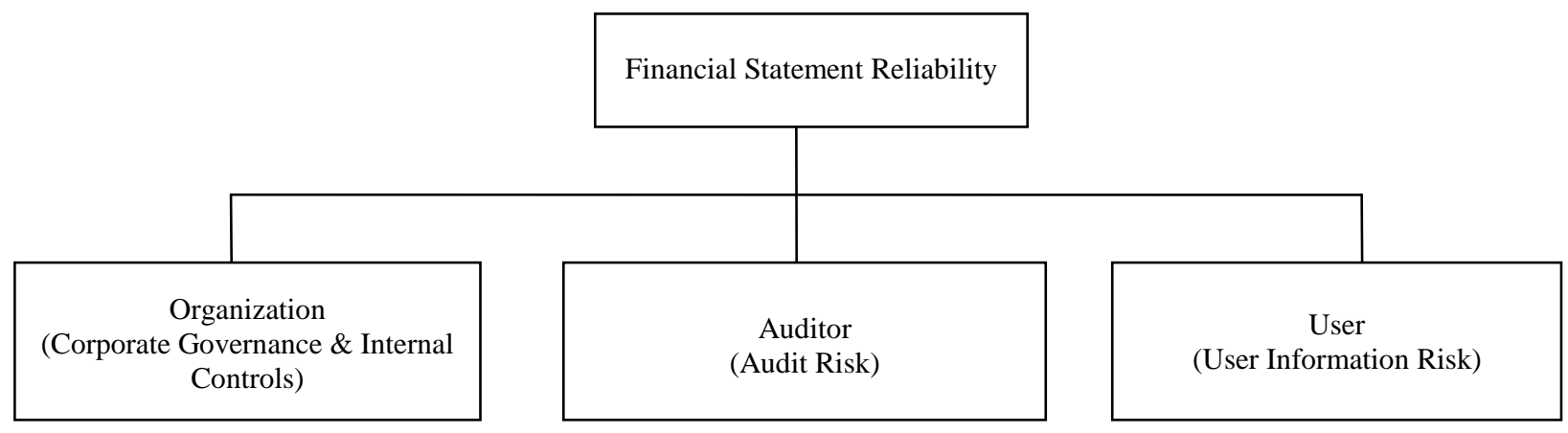




\section{User Information Risk}

The professionalism of the auditor and the quality of the audit process is an essential element affecting the reliability of financial statements. Accordingly, information about the auditor and the audit process is critical and should be available to help reduce the risk that the auditor either intentionally or unintentionally contributed to reducing the reliability of the financial statements. This risk has been identified as User's Information Risk (UIR). To reduce this risk, American users already demand that financial statements be prepared in accordance with generally accepted accounting principles. Furthermore, the audit should be conducted under the appropriate auditing standards so that users can have more confidence in the audit process.

Users have frequently requested supplemental information from organizations that is not required to be disclosed under generally accepted accounting principles. In many cases, users require the organization to provide the additional information as an addendum to financial statements. The federal government requires additional information about major grants and compliance with them. Regulatory agencies frequently require statistical data or schedules that provide more detail than are contained in general purpose financial statements. In other cases, users reduce their UIR by obtaining even greater financial data in the form of a separate document. The rule of thumb seems to be that users can reduce their UIR by obtaining more detailed information about the organization's finances.

Thus, the accounting profession has taken steps to incorporate more detailed information about the organization in the financial statements and related disclosures. However, one area of information that is still lacking is more information about the auditor. Even with adequate financial information about an organization, a neglectful auditor can taint the information to the user's detriment. The financial statements do not tell if the auditor has obtained a clean opinion under peer review standards, has adequate training in applicable areas, or even carries professional liability insurance coverage. Without reviewing the audit workpapers, the user cannot determine the extent of audit procedures performed or whether the auditors used professional care in performing their duties. The user relies on the accounting profession to police its own auditors.

Users want a high level of confidence in the professionals that conduct the audit. Auditors are required to use due professional care in conducting their work, and must maintain their technical proficiency in areas that are important to their clients. However, adequate consideration has not been given to the quality of the auditor when relying on financial statements. A lack of concern about the auditor can be harmful because a poor-quality auditor can readily produce a poor-quality audit.

U.S. auditing standards have been strengthened in the area of independence and the use of a risk-based approach. In addition, new peer review standards provide more "transparency" in the peer review reporting process so that the peer review report now refers to a letter of comments. These improvements are primarily the result of high-profile audit failures in recent years. Traditionally, the auditor has tried to control reliability issues by managing audit risk while the organization focuses on corporate governance and internal control issues. The user should have the ability to participate in this process by having the opportunity to evaluate "User Information Risk" (UIR).

The measurement of UIR is based on the evaluation of the five factors presented in the following model:

$\mathrm{UIR}=\mathrm{f}(\mathrm{TE}, \mathrm{MAT}, \mathrm{AT}, \mathrm{APR}, \mathrm{PLI}$,

where:

$\mathrm{TE}=$ Auditor's training and experience

MAT $=$ Dollar threshold of materiality

$\mathrm{AT}=$ Auditor's tenure on the engagement

$\mathrm{APR}=$ Summary of auditor's latest peer review

PLI= Extent of professional liability insurance carried by auditor 


\section{Auditor's Training and Experience Disclosure}

To improve audit quality, the auditor should possess the technical expertise needed to conduct the audit in a professional manner. Under auditing standards generally accepted in the U.S., the first general standard pertains to auditor fitness. The standard states that "the audit is to be performed by a person or persons having adequate technical training and proficiency as an auditor (AICPA - AU Section 210.01)." This standard encompasses the assumption that the auditor must have the training, experience, and skill in those particular areas that pertain to the organization being audited.

There is no fool-proof way for a user to be certain that an auditor has the technical proficiency needed to perform a quality audit. However, to communicate information about the auditor's training and experience, auditing standards should require the auditor to attach his or her professional history as a supplement to the audit report. The attachment should inform the reader about the auditor's professional experience as well as recent training that supports the qualifications of the auditor. In this way, the user can better understand the qualifications of the principal audit team.

Attaching qualification information is already used by other professionals when submitting opinion-type documents. To provide assurance that the auditor is competent, information should be made available to the user to assess whether the auditor has obtained pertinent and applicable training. Some users have established minimum continuing education requirements that go beyond the requirements of generally accepted auditing standards. For example, practitioners performing audits under Government Auditing Standards must have at least 24 hours of governmental continuing education every two years. It seems plausible this trend would continue so that specific training is demanded of auditors.

\section{General Audit Procedures Training}

Auditor training can protect and benefit the auditor. This training may alert the auditor to updates on audit techniques, industry trends, and common audit deficiencies. A wide disparity of auditor proficiency results when an important area such as training is left up to the judgment of the auditor. Another complication results from the CPE requirements that vary from state to state and nation to nation. Therefore, another benefit to attaching information about auditor training is that, over time, users would likely gravitate to a more standardized set of minimum CPE requirements. Users and related associations become the "consumer" demanding certain minimum auditor training standards. If there were a mechanism for users to ascertain the training and experience of the auditor, then users could feel more comfortable about the auditor's abilities.

\section{Materiality Disclosure}

A second factor of UIR pertains to the concept of materiality. Materiality is determined by the auditor and is used in both the planning and evaluation phases of the audit. In developing materiality levels, the auditor should consider both quantitative and qualitative factors and take into consideration the views of multiple users.

An inherent risk in the determination of materiality arises because there could be a great deal of variation of what constitutes materiality. It is a known fact that materiality may vary from audit firm to audit firm, client to client and from user to user. Items of financial interest might not be disclosed if the auditor, in his or her judgment, determines the item is not material. However, that same information might be of substantial interest to the user even though the amount was not deemed material enough for disclosure by the auditor. Of course, another auditor might establish a lower threshold of materiality and disclose the item. Thus, users would have more confidence in the audit if they knew the materiality threshold. Disclosure of quantitative materiality information could help users to avoid this confusion.

\section{Auditor Tenure Disclosure}

The effect of auditor tenure on audit quality has been a matter of debate for several years. A recent study concluded that fraudulent financial statement reporting was lower when the auditors had greater tenure (Carcello and 
Nagy, 2004). These findings mirror another study that measured the perception of quality on the part of users of financial statements as a function of auditor tenure (Ghosh and Moon, 2005). This research concluded that investors, independent rating agencies and analysts, had more confidence in financial statements where the auditors had a longer relationship with the client. Therefore, disclosure of audit tenure could prove to be valuable in the evaluation of UIR.

\section{Peer Review Disclosure}

The standards require auditors to undergo a quality/peer review to assess whether their quality control system can provide reasonable assurance that the firm will not conduct poor quality audits. Areas covered by peer review standards include: acceptance of clients, training, hiring, engagement procedures, and monitoring. The peer review movement has shown a degree of success over its history; however, there have been many criticisms of the process, especially in the wake of the Sarbanes-Oxley hearings.

For example, firms that belong to the American Institute of CPAs (AICPA) and perform audits under Government Auditing Standards must undergo a peer review every three years. However, what remains are firms that do not belong to the AICPA and also firms that perform audits in those states that do not require peer reviews of its members. If the firm belongs to the SEC practice section of the AICPA, the peer review opinion and letter of comments are available to the public. However, this is relatively small number of the total practicing firms. Since most firms do not belong to this special section of the AICPA, their peer review opinion and letter of comments are not available.

Another problem rests in the peer review process itself, which many practitioners feel does not do an adequate job of weeding out poorly performing professionals. It was certainly distressing that the "Big 4" accounting firms received unmodified peer review opinions yet massive audit failures performed by these same firms have recently occurred. In the interest of communicating with the public, the report should contain a brief statement about the nature of peer reviews. Furthermore, the auditor should disclose whether the firm belongs to any special sections of the AICPA which would tell the reader that the audit firm is subject to additional requirements.

\section{Professional Liability Insurance Disclosure}

Another area in which users can find comfort is whether the auditor carries professional liability insurance. The existence or nonexistence of sufficient insurance coverage may be important information about the auditor. First, firms with several claims tend to be purged from coverage or charged ever-higher premiums. A high claim history may be caused by performing audits in risky situations or by performing poor-quality audits. Second, insurance provides a means to recover losses that result from reliance on deficient audits. Therefore, it would be of benefit to users of financial statements if there was disclosure about the firm's insurance coverage.

\section{CONCLUSION}

Audited financial statements are the basis for the communication of essential financial information. Accordingly, the reliability of the financial statements is of extreme importance to all parties involved in the process. Up to now, the organization and auditor have been the primary parties entrusted with insuring reliability. This paper recommends the user can, and should, play a prominent role in this process by being allowed to analyze the quality of the auditor and audit process. In order for the user of financial statements to ascertain whether the audit was conducted with quality, five critical factors about the auditor and the audit process need to be disclosed. First, there should be disclosure of the auditor's experience and/or training. Second, the auditor should disclose the dollar threshold for materiality so the user can determine the degree of precision of the audit. Third, the auditor should disclose the number of years on the audit engagement so the user can assess whether there has been sufficient tenure, auditor rotation, or possible opinion shopping. Fourth, the auditor should disclose whether they obtained a peer review and the nature and results of that peer review. Finally, the audit should disclose the professional liability insurance coverage carried by the auditor. This potential process is designed to involve the user and give them the opportunity to share the responsibility for reducing the risk of using financial information. These recommendations require sweeping changes to audit disclosures, not because there is more disclosure about the client, but because there are disclosures about the auditor. 


\section{AUTHOR INFORMATION}

Jack R. Ethridge is a professor in the Gerald W. Schlief School of Accountancy at Stephen F. Austin State University in Nacogdoches, TX. His areas of interest are auditing and financial.

Treba A. Marsh, professor, is the director of the Gerald W. Schlief School of Accountancy. Her areas of interest are governmental, financial and auditing.

\section{REFERENCES}

1. American Institute of Certified Public Accountants (AICPA). 1972. Codification of Auditing Standards and Procedures. Statement on Auditing Standards No. 1. New York, NY: AICPA.

2. Carcello, J. V., \& Nagy, A. L. (2004, September). Audit firm tenure and fraudulent financial reporting. Auditing, 23(2), 57-71.

3. Ghosh, A., \& Moon, D. (2005). Auditor tenure and perceptions of audit quality. The Accounting Review, $80(2), 585-612$. 
NOTES 